\title{
Featuring High Impact Polystyrene Composites Strengthened with Green Coconut Fiber Developed for Automotive Industry Application
}

\author{
Gilmara Brandão Pereira ${ }^{1}$, Glayce Cassaro Pereira ${ }^{1}$, Márcio Alves de Lima ${ }^{1}$, Brunno José \\ Silva de Jesus ${ }^{1}$, Ezequiel de Andrade Silva ${ }^{1}$, Kelly Cristina Coelho de Carvalho Benini ${ }^{2}$, \\ Cirlene Fourquet Bandeira ${ }^{1}$ and Sérgio Roberto Montoro ${ }^{1,3,{ }^{*}}$
}

\author{
${ }^{1}$ UniFOA, Centro Universitário de Volta Redonda, MEMAT, Mestrado Profissional em Materiais, Avenida \\ Paulo Erlei Alves Abrantes, 1325, Três Poços, Volta Redonda-RJ. Zip Code: 27240-560, Brazil \\ ${ }^{2}$ Fatigue and Aeronautical Materials Research Group, Department of Materials and Technology, UNESP - \\ Univ. Estadual Paulista, 12516-410 Guaratinguetá, São Paulo, Brazil \\ ${ }^{3}$ FATEC, Faculdade de Tecnologia de Pindamonhangaba, Rodovia Vereador Abel Fabrício Dias, 4010 - \\ Água Preta, Pindamonhangaba-SP. Zip Code: 12445-010, Brazil
}

\begin{abstract}
Studies focused on generating products able to reduce environmental impact have been put in place, and those aiming at finding polymeric composites strengthened with natural fibers stand out among them. A composite was strengthened with coconut fibers in the present study, since the generation of coconut residues has increased in Brazil due to coconut water industrialization.

The aim of the present study is to process a high impact polystyrene (HIPS) composite strengthened with coconut fiber and to verify its possible application in the automotive industry. Strengthened samples were prepared using coconut fibers in the proportions 10, 20 and 30\% fiber to develop such HIPS composite. Analyses were performed in order to set the density, Shore A hardness and impact resistance of the processed composites.

It was found that the density and Shore A hardness results in the HIPS did not change due to the addition of coconut fibers. However, it was observed that the impact resistance was reduced because of it. It was noteworthy that the decreased impact resistance did not preclude the use of the HIPS/coconut fiber composite, since it showed that such material can be used in parts free from strong mechanical stress such as those inside the automobiles. The use of coir HIPS also aimed at reducing costs related to the polymer's consumption and at reusing the waste (coconut husk) from coconut water industries.
\end{abstract}

Keywords: Composites, characterizations, coconut fiber, HIPS, Shore A hardness.

\section{INTRODUCTION}

The interest on developing new technologies to facilitate the use of low environmental impact products has been growing in the recent years. Thus, several studies using polymer composites have been conducted in order to assure environmental preservation. Research related to the use of natural fibers stand out among these studies [1, 2].

Between 1990 and 2009, Brazil went from the 10th to the 4th position among the largest coconut producers. The productivity and market growth prospect remains a trend [3]. One of the factors driving such expansion trend is the coconut water industrialization in Brazil. The increase in coconut water consumption also increased the demand for green coconut and, consequently, reduced the lifespan

*Address correspondence to this author at the FATEC, Faculdade de Tecnologia de Pindamonhangaba, Rodovia Vereador Abel Fabrício Dias, 4010

- Água Preta, Pindamonhangaba-SP. Zip Code: 12445-010, Brazil;

Tel/Fax: +55 12364887 56; E-mail: sergio.montoro@fatec.sp.gov.br,

sergio.montoro@foa.org.br of landfills because of the increased generation of coconut shell waste, which represents a risk to the environment [4].

The use of coconut fiber to produce composites is worth because it not only reduces the generation of waste, but because it is a cheap, natural and renewable process [4; besides it approaches the sustainability concept addressed in the present study.

Many polymers are prone to fracture $[5,6]$. The high impact polystyrene or HIPS, in turn, has increased fracture resistance and hardness due to a second polybutadiene phase (PB) [2]. The HIPS is a viable matrix for composite strengthening with natural fibers due to its softening point between 87 and $100^{\circ} \mathrm{C}$, partial solubility in hydrocarbons and ketones, as well as to its processing temperature below the natural fiber degradation temperature and easy processing [7].

As partly aforementioned, the choice for HIPS in the present study was made because its cost is lower than 
that of other thermoplastics. In addition, HIPS presents some advantages such as adequate hardness and easy processing. Besides, it can be processed at temperatures below cellulose's degradation temperature.

\section{MATERIALS AND METHODS}

\section{Composites}

All herein characterized composites were provided by UNESP/FEG - Univ. Estadual Paulista. The composites were processed using HIPS 825 by FINA Technology, Inc. (presents excellent thermal and mechanical resistance) and strengthened with coconut fibers in volume fraction $10 \%, 20 \%$ and $30 \%$ weight. The amounts of fibers used in the study were specified taking into account works described in the literature. It is also worth mentioning that the amounts of fibers studied are part of a preliminary investigation.

\section{Real Density Determination through Helium Picnometry}

The helium pycnometry technique was adopted to set the specific pure HIPS mass and the composite samples in different proportions. The real density analyzer Quantachrome Instruments brand, Ultrafoam $1200 \mathrm{e}$ model was used in the experiment. It was leased from the Composites Characterization Laboratory of DMT / UNESP / FEG. The test temperature was set at $20^{\circ} \mathrm{C}$ and the results were expressed as the arithmetic mean of the three readings applied to the same sample.

\section{Shore A Hardness Determination}

The portable hardness tester, brand CV Instrument Limited, model CV Shore Durometers - Analogue was used to find the Shore A hardness of both the pure HIPS and the fiber-added composite. It was leased from the Metrology Laboratory of Maxion Structural Components - Cruzeiro Unit, São Paulo State. The test temperature was set at $20^{\circ} \mathrm{C}$ and the results were expressed as the arithmetic mean of the three readings applied to the same sample.

\section{Impact Strength Determination}

The impact machine Canti Lever XJU-22 Izod type (with $5.5 \mathrm{~J}$ hammer) was used to set the impact resistance of both the pure HIPS and fiber-added composites. It was leased from the Mechanical Testing
Laboratory of São Paulo University (USP / EEL / Area 2). Specimens presenting dimension $12 \times 55 \times 3 \mathrm{~mm}$ were used in the experiment and the results were expressed as the arithmetic mean of the five tested specimens.

\section{RESULTS AND DISCUSSION}

\section{Specific Mass}

The addition of coir HIPS did not lead to increased density in the processed composites when it was compared to the pure HIPS through the helium pycnometer analysis, as shown in Table 1. These results were interesting, since parts made out of composites strengthened with coconut fibers showed practically the same weight they had when they were made out of pure HIPS. However, the use of $30 \%$ coconut fiber $\left(\rho=1.1151 \mathrm{~g} / \mathrm{cm}^{3}\right)$ in the composite resulted in $70 \%$ reduction in pure HIPS consumption $\left(\rho=1.1064 \mathrm{~g} / \mathrm{cm}^{3}\right)$ and, consequently, in part production cost reduction.

Table 1: Specific Mass Results Found through Helium Pycnometry Analysis

\begin{tabular}{|c|c|}
\hline SAMPLES & Specific mass $\left(\mathbf{g} / \mathbf{c m}^{3}\right)$ \\
\hline \hline Pure HIPS & $1.1064 \pm 0.0074$ \\
\hline Coconut fiber & $1.5844 \pm 0.0098$ \\
\hline CT-10 & $1.1281 \pm 0.0123$ \\
\hline CT-20 & $1.1589 \pm 0.0018$ \\
\hline CT-30 & $1.1151 \pm 0.0032$ \\
\hline
\end{tabular}

\section{Shore A Hardness}

The results found through hardness analysis showed that HIPS did not change its property when it was added with coconut fiber. The composites and the pure HIPS have shown results able to classify the HIPS, composites and the very hard materials, because they presented hardness values between 90 and 100 Shore A [8]. Table 2 shows the Shore A

Table 2: Shore Hardness Results of Pure HIPS and HIPS/Coconut Fiber Composite

\begin{tabular}{|c|c|}
\hline SAMPLES & Shore A Hardness \\
\hline \hline Pure HIPS & $97.7 \pm 0.8$ \\
\hline CT-10 & $97.7 \pm 0.6$ \\
\hline CT-20 & $97.0 \pm 1.0$ \\
\hline CT-30 & $98.0 \pm 1.0$ \\
\hline
\end{tabular}


hardness results of the pure HIPS and of coconut fiber composites. The hardness results were satisfactory for the possible application of these composites in the automotive industry, since the addition of green coconut fibers did not significantly change the Shore A hardness in the HIPS.

\section{Impact Resistance}

The addition of coir HIPS showed impact resistance lower than that of the pure HIPS through the impact resistance tests. Table 3 shows the results of impact tests applied to the pure HIPS and to the CT-10, CT-20 and TC-30 composites.

The decreased impact resistance may have resulted from the strengthening process that have promoted composite ductility reduction. Thus, the fragile character of the composites worsens as the fiber volume increases. It is worth highlighting that ductility corresponds to the elongation of the total material due to plastic deformation.

Table 3: Impact Resistance Results of the Pure HIPS and HIPS/Coconut Fiber Composite

\begin{tabular}{|c|c|c|}
\hline SAMPLES & $\begin{array}{c}\text { Absorbed power } \\
(\mathbf{J})\end{array}$ & $\begin{array}{c}\text { Impact Resistance } \\
\left(\mathbf{k J} / \mathbf{m}^{2}\right)\end{array}$ \\
\hline \hline Pure HIPS & $1.887 \pm 0.424$ & $57.095 \pm 12.917$ \\
\hline CT-10 & $0.726 \pm 0.105$ & $22.076 \pm 3.198$ \\
\hline CT-20 & $0.705 \pm 0.067$ & $21.456 \pm 2.032$ \\
\hline CT-30 & $0.636 \pm 0.095$ & $19.350 \pm 2.907$ \\
\hline
\end{tabular}

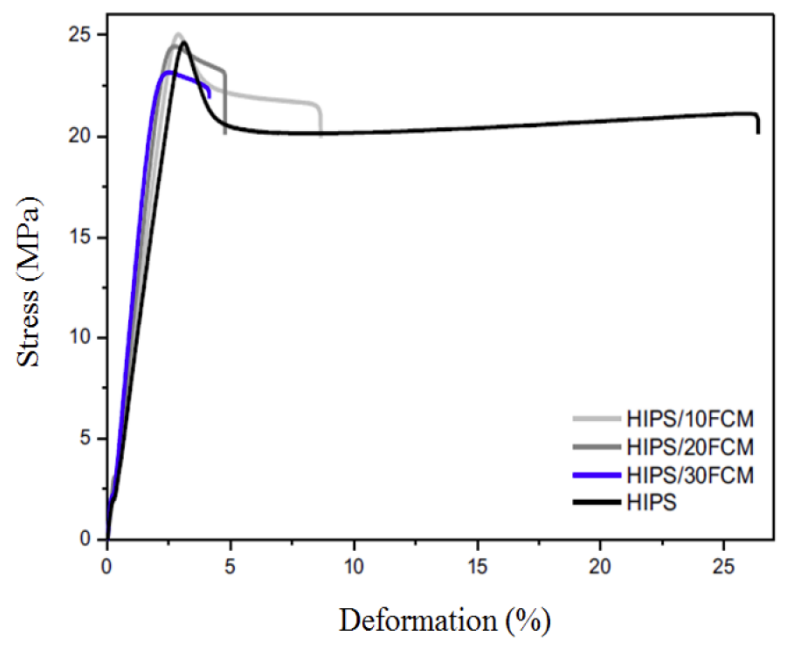

Figure 1: Stress and Deformation Graph of HIPS and HIPS/green coconut fiber composites [9].

The study conducted by Benini (2011) [9] showed through tensile tests that the addition of coconut fibers to the HIPS polymer matrix overall did not change material deformation to maximum voltage (portion related to the elastic deformation), but it caused approximately $85 \%$ reduction in total material deformation, as shown in Figure 1.

Yet, according to Benini (2011) [9], the increased fiber volume made it possible observing total elongation reduction in the composite, as shown in Table 4.

Table 4: Total Elongation of the Pure HIPS and of Coconut Fiber-Added Composites from the Study by BENINI (2011) [9]

\begin{tabular}{|c|c|}
\hline SAMPLES & TOTAL ELONGATION (\%) \\
\hline \hline Pure HIPS & $26.2 \pm 8.1$ \\
\hline CT-10 & $9.4 \pm 0.7$ \\
\hline CT-20 & $5.0 \pm 0.3$ \\
\hline CT-30 & $3.8 \pm 0.2$ \\
\hline
\end{tabular}

According to the mentioned study by Benini (2011) [9], such phenomenon can be associated with the material ductility reduction caused by the strengthening process and, consequently, with impact resistance reduction, as shown in Table 3.

The decreased hardness of composites added with coconut fibers can also justify the impact resistance reduction. It is worth highlighting that hardness corresponds to the material's ability to absorb energy until breaking. It is represented by the area below the stress $x$ strain curve, as shown in Figure 1.

\section{CONCLUSIONS}

By analyzing the results herein found, it was possible assessing the effect of coconut fiber addition to HIPS on some properties of HIPS composites strengthened with these fibers, as well as the possible application of these composites in the automotive industry.

The addition of coir HIPS did not cause density increase in the processed composites when it was compared to that of the pure HIPS through the helium pycnometer analysis.

The addition of coir HIPS did not change the hardness values in the composite when it was compared to the pure HIPS through the Shore A hardness analysis. 
The addition of coir HIPS led to resistance impact lower than that of the pure HIPS, according to the impact resistance tests. Thus, it would be feasible using these composites in the automotive industry to produce parts to be assembled inside the automobile, because these materials would suffer less stress than the material used in the external parts. Examples of application in internal parts are coatings for sun visors, seats, roof lining and trunk lining, among others, since they do not require a sharp resistance percentage.

Thus, the coconut fiber addition to HIPS led to a material composed of up to $30 \%$ less polymer, but that has viable mechanical properties for certain HIPS applications wherein the cost and Shore A hardness are more important than the impact resistance.

\section{REFERENCES}

[1] Marinelli AL, Monteiro MR, Ambrósio JD, Branciforti MC, Kobayashi M, Nobre AD. Development of Polymeric Composites with Natural Fibers: A Contribution to the Sustainability of Amazon. Polímeros: Ciência e Tecnologia 2008; 18(2): 92-99. https://doi.org/10.1590/S0104-14282008000200005
[2] Silva R, Haraguchi SK, Muniz EC, Rubira AF. Applications of lignocellulosic fibers in polymer chemistry and in composites. Quim Nova 2009; 32(3): 661-671. https://doi.org/10.1590/S0100-40422009000300010

[3] Martins A, Toshiko W, Silva P, Borelli C, Marcicano J, Sanches R. Use of young nut coir fiber for textile applicability. Redige 2013; 4(2).

[4] Barbosa JRV, Ramires EC, Razera IAT, Frollini E. Biobased composites from tannin-phenolic polymers reinforced with coir fibers. Industrial Crops and Products, In press 2010. https://doi.org/10.1016/j.indcrop.2010.05.007

[5] Callister Jr. WD. Materials Science and Engineering: an Introduction. $5^{\mathrm{a}}$ ed. Rio de Janeiro, R: LTC 2002.

[6] Rovere J, Corrêa CA, Grassi VG, Pizzol MF. Morphological Characterization of High Impact Polystyrene (HIPS). Polímeros: Ciência e Tecnologia 2008; 18(1): 12-19. https://doi.org/10.1590/S0104-14282008000100007

[7] Levy Neto F, Pardini LC. Structural Composites: Science and Technology. São Paulo: Edgard Blucher 2006; p. 22.

[8] Finocchio MAF. Class notes. Available in $\mathrm{http}: / /$ paginapessoal.utfpr.edu.br/mafinocchio/disciplinas-dagraduacao/et35p-materiais-e-equipamentoeletricos/DUREZA.pdf. Acesso em 10/05/2016.

[9] Benini KCCC. Development and characterization of polimeric composites reinforce with lignocelulosic fibers: HIPS/ green coconut husk and sugarcane bagasse fibers. 2011. $125 \mathrm{f}$. Thesis (Master in Mechanical Engineering) - Faculdade de Engenharia do Campus de Guaratinguetá, Universidade Estadual Paulista, Guaratinguetá 2011. 